\title{
Inverse modelling for predicting both water and nitrate movement in a structured-clay soil (Red Ferrosol)
}

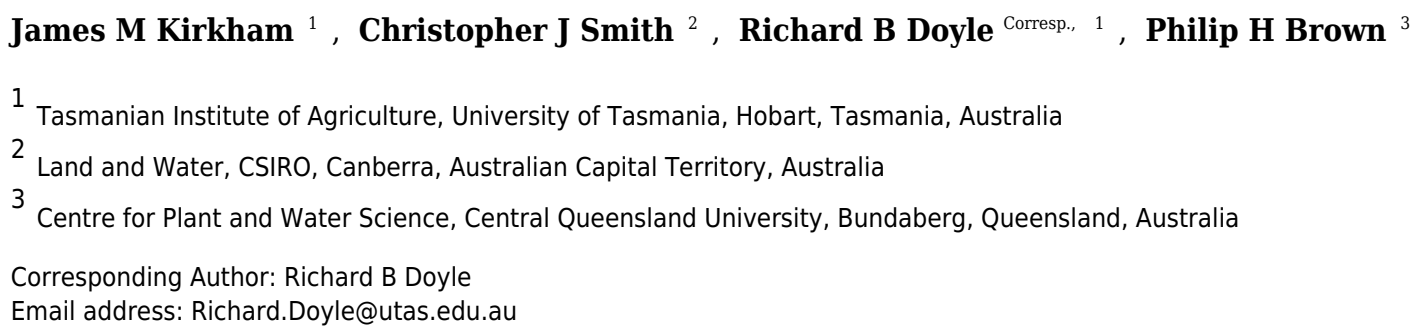

Soil physical parameter calculation by inverse modelling provides an indirect way of estimating the unsaturated hydraulic properties of soils. However many measurements are needed to provide sufficient data to determine unknown parameters. The objective of this research was to assess the use of unsaturated water flow and solute transport experiments, in horizontal packed soil columns, to estimate the parameters that govern water flow and solute transport. The derived parameters are then used to predict water infiltration and solute migration in a repacked soil wedge. Horizontal columns packed with Red Ferrosol were used in a nitrate diffusion experiment to estimate either three or six parameters of the van Genuchten-Mualem equation while keeping residual and saturated water content, and saturated hydraulic conductivity fixed to independently measured values. These parameters were calculated using the inverse optimisation routines in Hydrus 1D. Nitrate concentrations measured along the horizontal soil columns were used to independently determine the Langmuir adsorption isotherm. The soil hydraulic properties described by the van Genuchten-Mualem equation, and the $\mathrm{NO}_{3}{ }^{-}$adsorption isotherm, were then used to predict water and $\mathrm{NO}_{3}{ }^{-}$distributions from a point-source in two 3D flow scenarios. The use of horizontal columns of repacked soil and inverse modelling to quantify the soil water retention curve was found to be a simple and effective method for determining soil hydraulic properties of Red Ferrosols. These generated parameters supported subsequent testing of interactive flow and reactive transport processes under dynamic flow conditions. 


\section{Inverse modelling for predicting both water and nitrate movement 2 in a structured-clay soil (Red Ferrosol)}

3 James M. Kirkham ${ }^{\text {A }}$, Christopher J. Smith ${ }^{\mathrm{B}}$, Richard B. Doyle ${ }^{\mathrm{A}}$, and Philip H. Brown ${ }^{\mathrm{C}}$

4 ATasmanian Institute of Agriculture, University of Tasmania, Hobart, Tasmania, Australia

5 BLand and Water, CSIRO, Canberra, Australian Capital Territory, Australia

$6{ }^{\mathrm{C}}$ Centre for Plant and Water Science, Central Queensland University, Bundaberg, Queensland, Australia

7 DCorresponding author (Richard.Doyle@utas.edu.au). 


\section{Inverse modelling for predicting both water and nitrate movement \\ 11 in a structured-clay soil (Red Ferrosol)}

\section{Abstract}

13 Soil physical parameter calculation by inverse modelling provides an indirect way of estimating

14 the unsaturated hydraulic properties of soils. However many measurements are needed to provide

15 sufficient data to determine unknown parameters. The objective of this research was to assess the

16 use of unsaturated water flow and solute transport experiments, in horizontal packed soil columns,

17 to estimate the parameters that govern water flow and solute transport. The derived parameters are

18 then used to predict water infiltration and solute migration in a repacked soil wedge. Horizontal

19 columns packed with Red Ferrosol were used in a nitrate diffusion experiment to estimate either

20 three or six parameters of the van Genuchten-Mualem equation while keeping residual and

21 saturated water content, and saturated hydraulic conductivity fixed to independently measured

22 values. These parameters were calculated using the inverse optimisation routines in Hydrus 1D.

23 Nitrate concentrations measured along the horizontal soil columns were used to independently

24 determine the Langmuir adsorption isotherm. The soil hydraulic properties described by the van

25 Genuchten-Mualem equation, and the $\mathrm{NO}_{3}{ }^{-}$adsorption isotherm, were then used to predict water

26 and $\mathrm{NO}_{3}{ }^{-}$distributions from a point-source in two $3 \mathrm{D}$ flow scenarios. The use of horizontal

27 columns of repacked soil and inverse modelling to quantify the soil water retention curve was

28 found to be a simple and effective method for determining soil hydraulic properties of Red

29 Ferrosols. These generated parameters supported subsequent testing of interactive flow and

30 reactive transport processes under dynamic flow conditions.

31 Additional Keywords: Hydrus-1D, Hydrus-2D, Pedotransfer functions, rosetta, water flow 


\section{Introduction}

33 Simulation models are useful for examining water and solute movement in soil profiles, such as

34 when improving water and nutrient use efficiency or designing fertigation systems (Cote et al.

35 2003; Skaggs et al. 2004; Siyal and Skaggs 2009). There are a number of soil water models, such

36 as LeachM (Wagenet and Hutson 1989), Wet-Up (Cook et al. 2003), Hydrus 1D (Šimůnek et al.

37 2008), Hydrus 2D/3D (Šimůnek et al. 2006), and numerical procedures described by Wu and

38 Chieng (1995a; 1995b) which are all capable of describing water flow, and in some cases solute

39 transport, in one, two, or three dimensions. In this study, we selected the suite of Hydrus models,

40 because they can simulate solute flow under both $1 \mathrm{D}$ and 3D conditions. The van Genuchten-

41 Mualem water content, capillary pressure and hydraulic conductivity models were used to predict

42 water flow (Šimůnek et al. 2006), but physically realistic parameters are needed for the intended

43 application if accurate predictions are to be made.

44 Inverse optimisation techniques have become increasingly popular for parameter estimation and 45 many soil models now have user-friendly optimisation tools built in (Hopmans et al. 2002; Vrugt 46 and Bouten 2002; Wohling et al. 2008; Kandelous et al. 2011). The method involves multiple 47 calculations in which parameters are adjusted, using a method such as the Levenberg-Marquardt 48 or Bayesian procedure, until predictions agree sufficiently well with the measured data (Šimůnek 49 et al. 2006). This has advantages over other techniques for estimating hydraulic parameters, such 50 as pedotransfer functions, because the optimised parameters are estimated directly from measured

51 data for a particular soil hydrological problem of interest. Care however must be taken when using

52 this method to ensure parameters are physically realistic and representative of the spatial scale of

53 interest (Hopmans et al. 2002; Vrugt and Bouten 2002; Mallants et al. 2007; Wohling et al. 2008). 
54 Šimůnek et al. (2000) used inverse optimisation to estimate soil hydraulic parameters from water

55 content data measured in horizontal absorption columns. Similarly, inverse optimisation has been

56 used in Hydrus to predict water flow from water potential and cumulative outflow data (Van Dam

57 et al. 1994; Hopmans et al. 2002; Arbat et al. 2008). Kandelous and Šimůnek, (2010a,b) and

58 Kandelous et al. (2011) used inverse optimisation to estimate soil hydraulic parameters to predict

59 water distribution from a point source, including sub-surface irrigation, in the field. Mallant et al.

60 (2007) used Hydrus 2D and cumulative infiltration data from a deep borehole infiltration test in

61 clayey gravel and carbonated loess soil to estimate field-scale soil hydraulic properties.

62 Despite the increasing popularity of inverse optimisation, there are few published examples in

63 which parameters derived from unsaturated flow absorption columns have been tested in 3D flow

64 scenarios. Obtaining parameters for a specific flow scenario does not guarantee they will be

65 suitable for extrapolation outside the measured data set to which they were fitted (Sonnleitner $e t$

66 al. 2003). Vrugt and Bouten (2002) and Wohling et al. (2008) recommend the use of the

67 Metropolis algorithm to determine parameter uncertainty, given measurement errors and the

68 models inability to perfectly represent the system. However, if the derived parameters can be

69 shown to be capable of approximating the observed water content distribution under contrasting

70 conditions, it is likely they are physically realistic for the conditions being investigated. To this

71 end, Sonnleitner et al. (2003) and Kandelous et al. (2011) used inverse parameter estimation to

72 improve simulations of water content data under different flow scenarios. Minimising the number

73 of optimised parameters, increases the likelihood that the parameters are physically realistic

74 (Hopmans et al. 2002).

75 Although several numerical models, including Hydrus (Hanson et al. 2006), have looked at

76 reactive solute transport (Molinero et al. 2008; Kuntz and Grathwohl, 2009; Nakagawa et al. 
77 2010), validation of the models has been limited. Phillips (2006) used Hydrus and some

78 unpublished data to predict the transport of $\mathrm{K}^{+}$in unsaturated repacked horizontal columns of

79 reactive soil similar to the one used in this study. In field-scale simulations using Hydrus 1D,

80 Persicani (1995) and Moradi et al. (2005) had limited success in simulating reactive metal

81 movement over extended time-scales. However, Rassam and Cook (2002) were able to use

82 modelling of solute fluxes in soils to explain results from the field and laboratory measurements

83 of Rassam et al. (2002). Recently, Ramoss et al. (2011 and 2012) provide examples where Hydrus

84 was successfully used to predict water and solute movement under saline conditions. Validation

85 of the reactive solute module in Hydrus has received considerable attention; however a continued

86 effort is needed to demonstrate its ability to properly investigate soil hydrological processes and

87 reactive transport.

88 In this paper we use inverse parameter estimation to determine soil hydraulic properties from

89 measured water content profiles in horizontal soil columns (1D transport), and apply the

90 parameters to predicting water flow from a point source into a wedge of soil. We also investigated

$91 \mathrm{NO}_{3}{ }^{-}$transport, using an adsorption isotherm determined in the horizontal soil columns that were

92 subsequently used in Hydrus $2 \mathrm{D} / 3 \mathrm{D}$ to predict $\mathrm{NO}_{3}{ }^{-}$distributions in the soil wedge under two

93 different irrigation scenarios. 


\section{Materials and Methods}

95 Experiments used surface soil $(0-15 \mathrm{~cm})$ of a free-draining, well-structured Red, Mesotrophic,

96 Humose, Ferrosol (Isbell 1996). Soil was collected from Moina in northwest Tasmania, Australia

$97\left(41^{\circ} 29^{\prime} 28.80^{\prime}\right.$ S and $\left.14^{\circ} 60^{\prime} 34.70^{\prime \prime} \mathrm{E}\right)$ from a site under long-term pasture. Samples of soil were

98 air-dried at $40^{\circ} \mathrm{C}$, sieved to retain the $<2 \mathrm{~mm}$ fraction and stored for later use. Chemical and

99 physical properties are presented in Table 1.

100 Soil $\mathrm{pH}$ and EC were measured on 1:5 soil to water extracts (Rayment and Higginson, 1992).

101 Solution concentrations were measured from soil samples wet to a water content of $0.55 \mathrm{~g}_{\mathrm{w}} \mathrm{g}^{-1}$

102 soil. The solution was extracted by centrifuging samples with $10 \mathrm{~cm}^{3}$ of 1,1,2-trichloro-1,2,2-

103 trifluoroethane (TFE) as described by Phillips and Bond (1989). Exchangeable cations were

104 determined by extraction with $1 \mathrm{M} \mathrm{NH}_{4} \mathrm{Cl}$ after the water-soluble ions had been extracted. Organic

105 carbon was analysed using the Walkley and Black (1934) method. Particle size analysis (USDA;

106 Gee and Bauder 1986) was undertaken by pipette method after pretreatment to remove both

107 organic carbon and iron oxides using hydrogen peroxide and sodium dithionate respectively

108 (McKenzie et al. 2002). Semi-quantative mineralogy was determined using x-ray diffraction on

109 the pretreated clay fraction from the particle size analsyis.

\section{Horizontal Solute Absorption}

111 Absorption of $\mathrm{NO}_{3}^{-}$solution by the soil was measured in horizontal columns between 17 and 50

$112 \mathrm{~cm}$ in length depending on absorption periods. The air dry soil was moistened before packing into

113 the columns. Columns were packed (using a drop hammer) with relatively dry soil (water content

$1140.15 \mathrm{~g} \mathrm{~g}^{-1}$ ) in 2-3 $\mathrm{g}$ increments to achieve a bulk density of close to $1.03 \mathrm{~g} \mathrm{~cm}^{-3}$, which is similar

115 to that measured in the field. Using a Marriotte bottle, a $110 \mu \mathrm{mol}_{\mathrm{c}} \mathrm{cm}^{-3} \mathrm{NO}_{3}{ }^{-}$solution was applied 116 to the inlet of the soil column at zero suction. The outlet of the column remained open, tamped 
117 with cotton wool to hold the soil in place. Flow was stopped at set times and the column divided

118 into sections that ranged from 1 to $2.5 \mathrm{~cm}$. Short sections were place near the wetting front to

119 provide an accurate measure of the solute and water contents in this area. The soil sections were

120 transferred to tubes and weighed to determine moist weight.

121 Two types of column experiments were conducted, and are referred to as Set A and Set B. Each

122 individual experiment in both Set A and Set B used a freshly prepared soil column. Set A consisted

123 of five experiments with infiltration times of $26,30,43,47$ and 70 minutes. In these experiments,

124 water-soluble $\mathrm{NO}_{3}{ }^{-}$versus distance in the column was determined by adding deionised water to

125 each column section to make a soil-to-water ratio of 1:5.5 ( $\mathrm{SD} \pm 0.4)$. The soil plus water was

126 weighed. Samples were shaken for 4 hours in an end-over-end shaker, centrifuged at $9800 \mathrm{~m} \mathrm{~s}^{-2}$

127 for 10 minutes, and the supernatant decanted and weighed. The soil remaining in the tubes was 128 also weighed.

129 Set B involved four columns with absorption times for two of $80 \mathrm{~min}$ and $320 \mathrm{~min}$ for the others..

130 Duplicate columns in this series were either i) extracted as in Set A or ii) the soil solution was

131 extracted using the TFE method described by Phillips and Bond (1989). The adsorbed $\mathrm{NO}_{3}{ }^{-}$was

132 extracted by adding a volume of $2 \mathrm{M} \mathrm{KCl}$ to form a 1:5.5 ( $\mathrm{SD} \pm 0.5)$ soil:solution ratio (Rayment 133 and Higginson, 1992).

134 The tubes were reweighed and shaken for $1 \mathrm{~h}$ to extract adsorbed $\mathrm{NO}_{3}{ }^{-}$. The soil plus $2 \mathrm{M} \mathrm{KCl}$ 135 samples were centrifuged at $9800 \mathrm{~m} \mathrm{~s}^{-2}$ for $10 \mathrm{~min}$, and the supernatant decanted in pre-weighed 136 falcon tubes and weighed. The soil remaining in the tubes was washed twice by shaking for 30 $137 \mathrm{~min}$ in $20 \mathrm{~cm}^{3}$ deionised water to remove residual salts. The tubes were centrifuged at $9800 \mathrm{~m} \mathrm{~s}^{-2}$ 138 for $10 \mathrm{~min}$ and the wash solution discarded. The washed soil was oven-dried at $105^{\circ} \mathrm{C}$ and weighed 
139 to give the oven-dry mass of soil in each section. Water and $\mathrm{KCl}$ extracts were analysed for $\mathrm{NO}_{3}^{-}$

140 -N on an Alpkem autoanalyser (Alpkem 1992).

\section{Point-source solute infiltration}

142 Perspex wedges were constructed with the same dimensions described by Li et al. (2003) and 143 packed with dry soil (water content of $0.2 \mathrm{~g} \mathrm{~g}^{-1}$ ) to a bulk density of $0.95 \mathrm{~g} \mathrm{~cm}^{-3}$. All solutions

144 were applied to the $15^{\circ}$ corner of the wedge at a depth of $5 \mathrm{~cm}$ (Fig. 1) with a peristaltic pump set

145 to deliver solution at $50 \mathrm{~cm}^{3} \mathrm{~h}^{-1}$, equivalent to a dripper output of $1200 \mathrm{~cm}^{3} \mathrm{~h}^{-1}$ in a $360^{\circ}$ flow 146 environment.

147 Figure 2 shows the two irrigation scenarios applied to the wedge experiments. Both treatments 148 were irrigated for $0.5 \mathrm{~h}$ (equivalent to $25 \mathrm{~cm}^{3}$ of solution) with the $\mathrm{NO}_{3}{ }^{-}$solution applied to the 149 horizontal columns, i.e. $110 \mu \mathrm{mol}_{\mathrm{c}} \mathrm{NO}_{3}{ }^{-} \mathrm{cm}^{-3}$. This was immediately followed by a $1.5 \mathrm{~h}$ 150 application of solute free water $\left(75 \mathrm{~cm}^{3}\right)$. The soil was either i) sampled immediately after the 151 water application (Scenario A) or ii) allowed to rest for $16 \mathrm{~h}$ before irrigating again with water for

$1526 \mathrm{~h}\left(300 \mathrm{~cm}^{3}\right)$ prior to sampling (Scenario B). That is, a total of $375 \mathrm{~cm}^{3}$ of water was applied to 153 the wedge in Scenario B with samples being taken 24 hours after initial application of the solute.

154 A single replicate was used for Scenario A and Scenario B was duplicated.

155 Soil was sampled using the method described by Li et al. (2003). Briefly, a $5 \mathrm{~cm}$ grid was placed 156 over the column and a soil core $(2 \mathrm{~cm}$ internal diameter) taken from the centre of each grid. 157 Additional soil samples were taken at the edge of the wetting front. The soil from the core was 158 sub-sampled to determine gravimetric water content and total $\mathrm{NO}_{3}{ }^{-}$concentration (solution and 159 adsorbed). Wet soil was extracted with $2 \mathrm{M} \mathrm{KCl} \mathrm{(1:10} \mathrm{soil} \mathrm{:} \mathrm{KCl}$ ratio) and analysed on an Alpkem 160 autoanalyser (Rayment and Higginson 1992). Calculations of total $\mathrm{NO}_{3}^{-}$partitioned into the 
161 solution and the amount of adsorbed $\mathrm{NO}_{3}{ }^{-}$were done using the adsorption isotherm determined

162 from the horizontal column data (described below).

\section{Nitrate Adsorption Isotherm}

164 Partitioning of $\mathrm{NO}_{3}{ }^{-}$between the adsorbed and solution phases, over the range of soil solution 165 concentrations in the columns, was measured by displacing the soil solution with TFE (Philips and 166 Bond 1989). The Langmuir equation (equation 1) was then fitted to the data to describe the $\mathrm{NO}_{3}^{-}$ 167 adsorption isotherm.

$$
C_{a}=\frac{C_{\max } \phi C_{w}}{1+\phi C_{w}},
$$

168 where $C_{a}$ is the concentration of adsorbed solute $\left(\mu \mathrm{mol}_{\mathrm{c}} \mathrm{g}^{-1}\right), C_{w}$ is the concentration of solute in

169 the soil solution $\left(\mu \mathrm{mol}_{\mathrm{c}} \mathrm{cm}^{-3}\right), C_{\max }$ is the maximum amount of solute that can be adsorbed by the

170 soil $\left(\mathrm{g} \mathrm{cm}^{-3}\right)$, and $\phi$ determines the magnitude of the initial slope of the isotherm (Sposito, 1989).

$171 C_{\max }$ and $\phi$ were determined using the Gauss-Newton non-linear curve model in the statistical

172 program SAS (version 9.1). $C_{\max }$ and $\phi$ were determined to be 23.17 (95\% confidence interval

$173(\mathrm{CI}) \pm 3.43)$ and $0.00766(95 \% \mathrm{CI} \pm 0.00194)$ respectively.

\section{Hydrus Flow Equations}

175 Water flow is described by the Richards Equation modified to describe horizontal flow in one

176 dimension with no loss of water due to evaporation of root uptake (Simunek et al. 2008):

$$
\frac{\partial \theta}{\partial t}=\frac{\partial}{\partial x}\left(K \frac{\partial \psi}{\partial x}\right)
$$

177 where $\theta$ is the volumetric water content $\left(\mathrm{cm}^{3} \mathrm{~cm}^{-3}\right), \mathrm{t}$ is time $(\mathrm{min}), x$ is the horizontal distance

$178(\mathrm{~cm}), \psi$ is the water tension $(\mathrm{cm})$ and $K$ is the hydraulic conductivity $\left(\mathrm{cm} \mathrm{min}^{-1}\right)$ given by: 


$$
K(\psi, x)=K_{s a t}(x) K_{r}(h, x)
$$

179 where $K_{r}$ is the relative hydraulic conductivity (no unit) and $K_{s a t}$ is the saturated hydraulic

180 conductivity $\left(\mathrm{cm} \mathrm{min}^{-1}\right.$; Simunek et al. 2008).

181 The modified form of the Richards equation that describes water movement in two dimensions

182 assuming no loss of water through root uptake or evaporation can be written (Simunek et al. 2006):

$$
\frac{\partial \theta}{\partial t}=\frac{\partial}{\partial x_{i}}\left[K\left(K_{i j}^{A} \frac{\partial \psi}{\partial x_{j}}\right)+K_{i z}^{A}\right]
$$

183 where $x_{i}(i=1,2)$ are the spatial coordinates $(\mathrm{cm})$, and $K_{i j}{ }^{A}$ and $K_{i z}{ }^{A}$ are components of a

184 dimensionless anisotropy tensor $K^{A}$. Assuming flow is isotropic (that is, $K$ is equal in horizontal 185 and vertical directions) the diagonal entries of $K_{i j}{ }^{A}$ equal one and the off-diagonal entries equal

186 zero (Simunek et al. 2006).

187 In the two dimensional flow scenario $K$ is given by:

$$
K(\psi, x)=K_{\text {sat }}(x, z) K_{r}(h, x, z) .
$$

188 If the modified form of the Richards equation is applied to planar flow in a vertical cross

189 section, $x_{1}=X$ is the horizontal coordinate and $x_{2}=z$ is the vertical coordinate. This equation

190 can also describe axi-symmetric flow when $x_{1}=x$ represents a radial coordinate (Gardenas et

191 al. 2005). The transcripts $i$ and $j$ denote either the $x$ or $z$ coordinate.

192 To solve the Richards equation, Hydrus implements the soil hydraulic functions of the van

193 Genuchten-Mualem to describe unsaturated hydraulic conductivity in terms of soil water retention

194 parameters (Simunek et al. 2006). Water retention is described by Simunek et al. 2006 as: 


$$
\theta(\psi)= \begin{cases}\theta_{r} \frac{\theta_{s}-\theta_{r}}{\left[1+|\alpha \psi|^{n}\right]^{m}} & \psi<0 \\ \theta_{s} & \psi \geq 0\end{cases}
$$

195 and unsaturated conductivity is written (Simunek et al. 2006):

$$
K(\psi)=K_{s} S_{e}^{l}\left[1-\left(1-S_{e}^{1 / m}\right)^{m}\right]^{2} \quad \psi<0
$$

196 where:

$$
m=1-1 / n, \quad n>1
$$

197

and:

$$
S_{e}=\frac{\theta-\theta_{r}}{\theta_{s}-\theta_{r}}
$$

198 In the above equations $\theta_{r}$ is the residual water content $\left(\mathrm{cm}^{3} \mathrm{~cm}^{-3}\right), \theta_{s}$ is the saturated water content $199\left(\mathrm{~cm}^{3} \mathrm{~cm}^{-3}\right), \alpha\left(\mathrm{cm}^{-1}\right), n$ (no unit) and $l$ (no unit) are curve fitting parameters for the hydraulic 200 conductivity function and $S_{e}$ is the effective water content $\left(\mathrm{cm}^{3} \mathrm{~cm}^{-3}\right)$.

201 When the van Genuchten-Mualem model is used to solve Richards equation in Hydrus there are 202 six soil hydraulic parameters required $\left(\theta_{r}, \theta_{s}, \alpha, n, l\right.$ and $\left.K_{s a t}\right)$.

203 The Langmuir equation was used to predict the reactive solute transport. In Hydrus, desorption of 204 a non-transforming solute is described by the generalised non-linear equation (Šimůnek et al. 205 2006):

$$
C_{a}=\frac{k_{s} C_{w}^{\omega}}{1+\phi C_{w}^{\omega}},
$$

206 and: 


$$
\begin{aligned}
\frac{\partial C_{a}}{\partial t}= & \frac{k_{s} \omega C_{w}^{\omega-1}}{\left(1+\phi C_{w}^{\omega}\right)^{2}} \frac{\partial C_{w}}{\partial t}+\frac{C_{w}^{\omega}}{1+\phi C_{w}^{\omega}} \frac{\partial k_{s}}{\partial t}-\frac{k_{s} C_{w}^{2 \omega}}{\left(1+\phi C_{w}^{\omega}\right)^{2}} \frac{\partial \phi}{\partial t} \\
& +\frac{k_{s} C_{w}^{\omega} \ln C_{w}}{\left(1+\phi C_{w}^{\omega}\right)^{2}} \frac{\partial \omega}{\partial t},
\end{aligned}
$$

207 where $k_{s}\left(\mathrm{~cm}^{3} \mathrm{~g}^{-1}\right), \omega$ (dimensionless), and $\phi\left(\mathrm{cm}^{3} \mathrm{~g}^{-1}\right)$ are constants. In the case of the Langmuir

208 equation, $k_{s}=C_{\max } \phi$ (where $C_{\max }$ and $\phi$ are the Langmuir equation constants from equation 1)

209 and $\omega=1$.

\section{Estimation of Flow Equations Parameters}

211 Soil hydraulic parameters for the van Genuchten equation were determined using the inverse

212 optimisation procedure in Hydrus 1D (Šimůnek et al. 2008). Water profile data from the soil

213 columns in Set A were used, after removing obvious outliers in the data that were determined to

214 be due to soil loss during column sampling (Hopmans et al. 2002). The initial water content was

215 set to $0.15\left(\mathrm{~cm}^{3} \mathrm{~cm}^{-3}\right)$, the measured water content of the repacked columns, for all optimisations.

216 Free water absorption was simulated by applying constant water content boundary condition of

$2170.64\left(\mathrm{~cm}^{3} \mathrm{~cm}^{-3}\right)$ to the opening of the column. The lower boundary condition was set to free

218 drainage. The maximum number of iterations was set to 50 and 86 water content points across 5

219 time steps were used in the inverse scenario from the Set A column experiments. Weighting of

220 inverse data was by standard deviation and an equal weighting was applied to all the water content

221 values. Residual soil water content $\left(\theta_{r}\right), \theta_{s}$, and $K_{s a t}$ were set or optimised depending on the

222 optimisation scenario (Fit All is the term applied when all parameters were optimised and Set

223 Measured is used when $\theta_{r}, \theta_{s}$ and $K_{\text {sat }}$ were set to independently measured values). The remaining

224 empirical parameters, $\alpha, n$, and $l$ were fitted by running the inverse parameter estimation option in

225 Hydrus 1D. The initial values of $\alpha, n$, and $l$ were based on the default values given for the Loam

226 soil in Hydrus $1 \mathrm{D}(\alpha=1.56, n=0.173$, and $l=0.5)$. 
227 Initial estimates for $\theta_{r}$ and $\theta_{s}$ were 0.05 and $0.58\left(\mathrm{~cm}^{3} \mathrm{~cm}^{-3}\right)$ and $K_{\text {sat }}$ was set to $0.10 \mathrm{~cm} \mathrm{~min}^{-1}$.

228 Saturated soil water content $\left(\theta_{s}\right)$ and $K_{\text {sat }}$ values were independently measured in falling head $K_{\text {sat }}$

229 experiments (Reynolds et al. 2002). A column of water (4.2 cm in diameter and $12 \mathrm{~cm} \mathrm{high)} \mathrm{was}$

230 applied to wet repacked soil core packed to a bulk density of 1.0 with air dry soil sieved to $<2 \mathrm{~mm}$.

231 The soil cores were $2 \mathrm{~cm}$ high and had an internal diameter the same as the water column sitting

232 above it. Triplicate measurements of conductivity were recorded on four separate cores. Residual

233 soil water content $\left(\theta_{r}\right)$ was estimated based on the air-dry soil water content.

234 The Rosetta pedotransfer function model (Schaap et al. 2001) was used to estimate soil hydraulic

235 properties as a comparison against the inverse modelling method. The soil particle size

236 measurements (Table 1) and bulk density $\left(1.03 \mathrm{~g} \mathrm{~cm}^{-3}\right)$ were used to estimate soil hydraulic

237 parameters. In a second prediction, moisture retention at -33 and $-1500 \mathrm{kPa}\left(0.34\right.$ and $0.22 \mathrm{~cm}^{3}$

$238 \mathrm{~cm}^{-3}$, respetively) were also included as inputs into Rosetta. The water content at $-33 \mathrm{kPa}$ was

239 determined on a suction table apparatus and $-1500 \mathrm{kPa}$ were determined using pressure plate

240 apparatus (Cresswell 2002).

241 Modelling Water and Solute Absorption in Soil Wedges

242 Hydrus 2D/3D was used to model water distribution in the horizontal column experiments based

243 on the same initial and boundary conditions used in Hydrus 1D during inverse optimisation.

244 Horizontal flow in Hydrus 2D/3D was simulated by setting the geometry to a 2D horizontal plane.

245 The geometry of the flow domain was set to a column $2 \mathrm{~cm}$ in diameter and $50 \mathrm{~cm}$ long. Soil

246 hydraulic parameters having the lowest values for the objective function were used to simulate

247 water absorption. Nitrate absorption was predicted by applying a third-type (Cauchy) solute

248 boundary at the inlet of the column $(x=0 \mathrm{~cm})$ at a constant concentration of $110 \mu \mathrm{mol} \mathrm{NO}_{3}{ }^{-} \mathrm{cm}^{-3}$.

249 Bulk density was set to the measured value of $1.03 \mathrm{~g} \mathrm{~cm}^{-3}$, longitudinal and transverse 
250 dispersivities were set to 0.3 and $0.03 \mathrm{~cm}$, respectively (Ajdary et al. 2007), and the diffusion

251 coefficient was neglected as it was considered negligible relative to the dispersion (Hanson et al.

252 2006; Ajdary et al. 2007). Parameters for the Langmuir equation (equation 1) to describe $\mathrm{NO}_{3}{ }^{-}$

253 adsorption were determined from the data measured in column Set B.

\section{Modelling Water and Solute in Horizontal Columns}

255 To simulate water and $\mathrm{NO}_{3}{ }^{-}$distribution in the wedge experiments, a $40 \times 40 \mathrm{~cm}$ flow domain was

256 created in a 2D axi-symmetrical vertical flow geometry. The infiltration point at $5 \mathrm{~cm}$ depth was

257 represented by a semicircle with $3 \mathrm{~cm}$ radius. The flux from the source was $10.61 \mathrm{~cm} \mathrm{~h}^{-1}$ (equation 258 4), equivalent to a dripper output of $1200 \mathrm{~cm}^{3} \mathrm{~h}^{-1}$.

$$
\sigma=\frac{Q}{4 \pi r^{2}}
$$

259 where $\sigma$ is the flux from the surface of the source $\left(\mathrm{cm} \mathrm{h}^{-1}\right), Q$ is the total volumetric flux $\left(\mathrm{cm}^{3} \mathrm{~h}^{-}\right.$

$\left.260^{1}\right)$, and $r$ is the radius of the spherical source $(\mathrm{cm})$.

261 The finite element mesh of the flow domain, which determines the level of model resolution in the 262 calculations, was set to $0.5 \mathrm{~cm}$ in both $\mathrm{z}$ and $\mathrm{h}$ directions. No flux was allowed through the column 263 boundaries. The infiltration source was set as a variable flux boundary so that water and solute 264 applications could be controlled according to the two irrigation scenarios described for the wedge 265 columns (Fig. 2). Nitrate absorption was predicted in the same way as for the horizontal columns. 266 The time-variable boundary condition was used to apply the solute $\left(110 \mu \mathrm{mol}_{\mathrm{c}} \mathrm{NO}_{3}^{-} \mathrm{cm}^{-3}\right)$ only 267 for the first $0.5 \mathrm{~h}$ of water application to the column.

\section{Statistical Analysis}

269 The root mean square error (RMSE) was calculated as the error between the measured and 270 simulated water content and $\mathrm{NO}_{3}^{-}$concentrations. Comparisons of the RMSE values with 
271 predictions from different parameter sets allowed those that produced the lowest errors to be

272 identified. Comparisons of simulated RMSE values with those calculated from measured data

273 allowed the significance of the model error to be assessed in relation to measurement error. This

274 method has been commonly used to measure the quality of model predictions in previous studies

275 (Skaggs et al. 2004; Ajdary et al. 2007; Arbat et al. 2008; Patel and Rajput 2008). Part of the

276 inverse modelling in Hydrus 1D allows calculation of a correlation matrix that specifies the

277 correlation between the fitted coefficients and statistical information about the fitted parameters.

\section{Results}

279 Parameter determination and model validation in horizontal columns

280 Values for soil hydraulic parameters estimated from column Set A are presented in Table 2. The

281 two inverse scenarios produced slightly differing values, with the Fit All parameters having a lower

282 value for the objective function $\Phi$ than the Set Measured suggesting that the former gave a slightly

283 closer fit between the predicted and measured soil water profiles. The $95 \%$ confidence intervals

284 for the optimised values for $\alpha, n$, and $l$ where smaller compared to the values when all parameters

285 were optimised. The parameters in the Fit All scenario had higher uncertainty and greater

286 correlation between fitted parameters compared to the Set Measured parameters (Table 2 and 3).

287 The correlation matrix shows there were three high values in the Fit All parameter function

288 compared to one in the Set Measured results; $\alpha$ and $n$ being highly correlated (Table 3, bold

289 entries). High correlation values (magnitude $>0.9$ ) indicate parameter non-uniqueness and a

290 correspondingly high uncertainty (Hopmans et al. 2002; Šimůnek and van Genuchten, 1996). The

291 optimised value of $\theta_{r}$ was 0.112 and the $95 \%$ confidence interval that ranged from -0.135 to 0.359 ,

292 which includes the measured value $(0.054 \pm 0.003)$. Saturated water content $\left(\theta_{s}\right)$ was $0.56(0.553$

293 to 0.567$)$ and was significantly different from the independently measured values $(0.58 \pm 0.04$; 
294 Table 2$)$. The measured $K_{\text {sat }}(0.104 \pm 0.0299)$ fall within the $95 \%$ confidence interval $(0.054$ to

295 0.176; mean best fit value of 0.115 ) of the optimised value.

296 The two parameter sets were tested against independently measured data from the horizontal

297 columns (Column data Set B) and the point-source wedge experiments. Predicted water

298 distributions and measured water content in the horizontal columns from column Set B are shown

299 in Figure 3A. We have plotted $\theta$ and $\mathrm{NO}_{3}{ }^{-}$profiles against the Boltzmann variable $X$ 300 (distance/ $\sqrt{\text { time}}$; $\mathrm{cm} \mathrm{s}^{-1 / 2}$; Smiles et al. 1978; Philips and Bond 1989). Both parameter sets showed

301 similarly good correspondence to the measured data (continuous and dotted lines), which is 302 confirmed by the RMSE and $R^{2}$ values (Table 4). Accurate predictions of $\theta$ profiles after absorbing 303 water for 80 and 320 minutes are not surprising given that data from Set A (27 to 70 minutes) are 304 not statistically different from Set B when normalised against the Boltzmann variable. The results 305 however do show that under the unsaturated absorption scenario, predictions made for longer times 306 (80 and 320 minutes) are still accurate when the predictions are extended beyond the range of 307 optimised data. The consistency between predictions based on short time $\theta$ and $\mathrm{NO}_{3}{ }^{-}$data (Set A) 308 and longer time $\theta$ and $\mathrm{NO}_{3}{ }^{-}$data (Set $\mathrm{B}$ ) further demonstrate the experiments had a good degree of 309 repeatability and produced consistent data across a range of time scales.

310 In comparison, predicted water content using soil hydraulic parameters determined by Rosetta are

311 shown in Fig. 4. These data show the piston front to be significantly behind the measured data

312 (combined data from column Set A and B) especially when the water content at -33 and $-1500 \mathrm{kPa}$

313 are included in the model. Removal of the iron oxides $(\mathrm{FeO})$ before determining the sand, silt and

314 clay content did not improve the predictions of water retention parameters or saturated hydraulic

315 conductivity. Deriving the water retention parameters and saturated hydraulic conductivity with

316 Rosetta, values that use pedotransfer functions to predict the Van Genuchten parameters, produced 
317 significant inaccuracies in the predictions (see Fig 4). In these experiments they are certainly less

318 accurate than parameters derive from inverse modelling (Fig. 3).

319 The predicted $\mathrm{NO}_{3}{ }^{-}$distribution is shown in Fig. 3B. The measured and predicted $\mathrm{NO}_{3}^{-}$

320 distributions were compared from both Set A (27-70 minutes) and Set B (80 and 320 minutes)

321 because the $\mathrm{NO}_{3}{ }^{-}$distribution was not used in the inverse optimisation. The good prediction of

$322 \mathrm{NO}_{3}{ }^{-}$distribution by the two parameter sets, when the Langmuir isotherm parameters were

323 included in the simulations, is confirmed by the $R^{2}$ and RMSE values (Table 4). Due to the

324 inaccuracy of water content prediction using Rosetta, no $\mathrm{NO}_{3}{ }^{-}$data are presented.

325 Model validation using $3 D$ wedge infiltration

326 The predicted distributions of water and $\mathrm{NO}_{3}{ }^{-}$throughout the soil wedge after the two irrigation

327 scenarios are shown in Fig. 5. This figure also shows the positions of horizontal and vertical

328 transects presented in Figs. 6 and 7. These figures show the agreement between the measured and

329 predicted water and $\mathrm{NO}_{3}{ }^{-}$profiles in the wedge. Comparisons of the RMSE and $R^{2}$ calculations

330 indicated that both the Fit All and Set Measured parameter sets predicted very similar distributions,

331 although the Fit All parameters produced slightly better predictions of $\mathrm{NO}_{3}{ }^{-}$distribution in the

332 longer irrigation scenario. The measured RMSE, calculated from columns where duplicate

333 measurements were taken at identical times and locations, were similar to the RMSE of the

334 predicted values (Table 5). This indicates that the errors between the measured and predicted

335 values were very similar to the errors of replicate measurements at identical points and times in

336 the wedge experiments. The predictions achieved using the two parameter sets were therefore

337 considered to be suitable to estimate water and $\mathrm{NO}_{3}{ }^{-}$distribution in the point-source flow scenario

338 of the wedge column. The "Set Measured" parameters are preferred because there is less auto

339 correlation between the fitted parameters $(\alpha, n, l)$. 


\section{Discussion}

341 Inverse optimisation using Hydrus-1D can be used to effectively estimate soil hydraulic properties

342 from simple 1D flow experiments. The flow parameters derived from 1D columns were suitable

343 for describing flow under more complex 3D flow scenarios. These results show that the use of

344 absorption columns offers an alternative to pedotransfer function methods and has the advantage

345 that the parameters are determined using data from the actual soil type under consideration.

346 Comparisons of optimised parameters with independently measured data in the horizontal column

347 showed that the fitted parameters were able to accurately predict water distribution in these flow

348 scenarios. Further, water distribution could be accurately predicted for absorption periods four

349 times longer than the data used in the inverse optimisation. This provides preliminary evidence

350 that the parameters can predict water distribution outside the range of fitted values. However, this

351 result is not surprising because the measured water content profiles coalesce to a single curve when

352 presented against the Boltzmann variable $X\left(\mathrm{~cm} \mathrm{~s}^{-1 / 2}\right)$. Further evidence for this was provided by

353 testing the parameters in the alternative point-source 3D flow scenario. The results presented in

354 this paper demonstrate there is scope to use soil hydraulic parameters obtained from simple

355 horizontal absorption experiments to accurately estimate water flow under more complex 3D

356 conditions in uniform re-pack soil conditions (isotropic).

357 The inverse optimisations in this study produced two parameter sets that were capable of providing 358 good predictions of water flow in the two flow scenarios. Hopmans (2002) suggests that if various

359 parameter sets produce similar model outcomes, the soil hydraulic parameters may be

360 unidentifiable and the inverse optimisation may be ill-posed. However, our data (Table 2) shows

361 that the values identified in the two scenarios are within the $95 \%$ confidence interval estimates of

362 the predictions; the difference between the parameter sets are therefore not significant. Limiting 
363 the number of parameters optimised in the inverse procedure reduced the uncertainty of the fitted

364 parameters without significantly affecting the accuracy of model predictions. Further, the Fit All

365 scenario gave high correlations of three parameters in comparison to the one high value for the Set

366 Measured scenario (Table 3). Limiting the number of parameters in the inverse scenario was

367 shown to be advantageous because parameter variation was reduced. These findings are consistent

368 with the recommendations of Hopmans et al. (2002) but contrast with the study of Sonnleitner et

369 al. (2003). The latter work indicated that maximising the number of variables in the inverse

370 optimisation increased the ability of parameters to describe water flow in alternative scenarios.

371 In our wedge study, only minor differences were observed between predictions when the number

372 of optimised parameters was reduced. Furthermore, reducing the number of parameters in the

373 inverse optimisation was advantageous because parameter uncertainty was reduced (Table 2). Our

374 results show that, where practical, there is benefit in conducting additional measurements to

375 estimate $\theta_{s}$ and $K_{\text {sat }}$, which are two of the most sensitive parameters of the model (Arbat et al.

376 2008). The benefits of using measured parameters, in combination with inverse modelling of water

377 content data, has also been demonstrated by Kandelous et al. (2011). In these columns, hydraulic

378 conductivity is not independently measured; rather sorptivity is measured and the hydraulic

379 conductivity must be inferred with a model.

380 Including solute reaction parameters enables the Hydrus model to accurately predict reactive solute

381 distribution in the soil. The retardation in the $\mathrm{NO}_{3}{ }^{-}$relative to the inflowing water indicates that

382 the solute was adsorbed by the soil. Sorption of $\mathrm{NO}_{3}{ }^{-}$was included in Hydrus by using the

383 Langmuir equation to approximate the partitioning of $\mathrm{NO}_{3}{ }^{-}$between the soil solution and the

384 adsorbed phases. The Langmuir equation has been used previously to describe solute adsorption

385 in soil (Katou et al. 1996; Qafoku et al. 2000; Phillips 2006). 
386 The distribution of solutes adsorbed to soil during water flow has been simulated under point-

387 source infiltration in previous studies using Hydrus 2D/3D (Hanson et al. 2006). However

388 validation under these flow scenarios has received little attention. Ben-Gal and Dudley (2003)

389 observed that predictions of reactive $\mathrm{P}$ transport from a drip irrigation system showed a similar

390 distribution to measured data, but they did not make any statistical comparisons. Reactive solute

391 transport was previously validated under other flow scenarios (Persicani 1995; Moradi et al. 2005).

392 Our results validate the inclusion of the Langmuir equation in Hydrus for the prediction of reactive

393 solute movement for $1 \mathrm{D}$ and $3 \mathrm{D}$ flow conditions. Furthermore, the results show that reactive solute

394 parameters determined from relatively simple 1D adsorption columns can be used to accurately

395 predict solute distribution under 3D conditions.

396 Other studies that have used Hydrus to predict water movement through soils have utilised

397 pedotransfer functions (PTF) to estimate soil hydraulic parameters (Espino et al. 1995; Skaggs et

398 al. 2004; Li et al. 2005; Phillips 2006; Siyal and Skaggs 2009). The suitability of parameters

399 predicted by PTFs relies on the amount of data collected from soils with similar particle size

400 distribution, bulk density, and water-holding capacity. We investigated use of the Rosetta model

401 (Schaap et al. 2001) to obtain parameters for the same Red Ferrosol used here, but it provided less

402 accurate estimates of water distribution in comparison to parameters determined from inverse

403 modelling (Fig. 4). The high value of the pore connectivity parameter, 1 (Table 2), that resulted

404 from inverse optimisation is in contrast to the value of 0.5 used on the Rosetta model (Cook and

405 Cresswell, 2007)). This difference may explain the limitations of Rosetta to accurately predict

406 water flow in the repacked columns in these particular experiments.

407 This finding contrasts with those of Kandelous and Šimůnek (2010a) where parameters estimated

408 from Rosetta produced acceptable predictions of water movement in laboratory studies. The 
409 differing results in our study may be in part due to the limited data for Australian Red Ferrosols

410 available in the Rosetta soil database. In general, this paper confirms that inverse optimisation is

411 advantageous provided enough data has been collected over a sufficient range of water contents

412 (Šimůnek et al. 2000; Sonnleitner et al. 2003). The use of inverse optimisation applied to

413 horizontal infiltration columns provides a simple technique to accurately determine reaction

414 parameters.

415 If parameters determined from inverse optimisation are to successfully describe water flow in

416 alternative scenarios the soil properties must be the same. This was achieved in our laboratory

417 because careful packing was possible in both the horizontal columns and soil wedges. For a field

418 scenario, a similar method of predicting water and solute flow would need laboratory experiments

419 on undisturbed cores. Similarly, Kandelous and Šimůnek (2010a) found that parameters suitable

420 for describing water movement in packed laboratory columns were not capable of describing water

421 distribution in an undisturbed field soil.

\section{Conclusion}

423 Inverse modelling procedures in Hydrus confirm that soil hydraulic parameters can be reliably

424 obtained from simple 1D diffusive water uptake soil column studies. The derived parameters are

425 capable of accurately describing diffusive water movement over extended times and in alternative

426 dynamic flow scenarios to those in which they were fitted. These results demonstrate that simple

427 water uptake column experiments can be used to provide suitable flow conditions for accurate

428 determination of reaction parameters under dynamic flow conditions. Reducing the number of

429 parameters in the optimisation procedures by imposing independently measured values for $\theta_{\mathrm{s}}, \theta_{\mathrm{r}}$

430 and $\mathrm{K}_{\mathrm{sat}}$ decreased parameter uncertainty (or increased parameter uniqueness) without significantly

431 impacting the accuracy of model predictions. These results show there is merit in pursuing this 
432 method in more complex scenarios since it may provide a simpler and cheaper way of determining

433 hydraulic parameters in field conditions.

434 Solution $\mathrm{NO}_{3}{ }^{-}$and adsorbed $\mathrm{NO}_{3}{ }^{-}$concentrations collected from a combined water uptake- $\mathrm{NO}_{3}{ }^{-}$

435 tracer test provided the data to fit the reaction parameters for the Langmuir isotherm, which in turn

436 were included in the Hydrus model to predict reactive solute transport. We have demonstrated the

437 ability of HYDRUS to integrate unsaturated flow processes and independently determined reactive

438 transport processes based on independent experiments involving the complex interplay of dynamic

439 flow and reactive transport.

440

441 Acknowledgements: We thank Dr Freeman Cook for his assistance with Hydrus modelling and

442 Dr David Smiles for providing his expertise in experimental design and analysis.

443 


\section{References}

445 Ajdary K, Singh DK, Singh AK Manoj K (2007) Modelling of nitrogen leaching from 446 experimental onion field under drip fertigation. Agricultural Water Management 89, 15-28.

447 Alpkem. 1992. The flow solution. Alpkem Corporation, Wilsonville, OR.

448 Arbat G, Puig-Bargues J, Barragan J. Bonany J, Ramirez de Cartagena F (2008) Monitoring soil 449 water status for micro-irrigation management versus modelling approach. Biosystems $450 \quad$ Engineering 100, 286-296.

451 Ben-Gal A, Dudley LM (2003) Phosphorus availability under continuous point source irrigation. $452 \quad$ Soil Science Society of America Journal 67, 1449-1456.

453 Cook FJ, Thorburn PJ, Fitch P, Bristow P (2003) WetUp: a software tool to display approximate $454 \quad$ wetting patterns from drippers. Irrigation Science 22, 129-134.

455 Cook FJ, Cresswell HP (2007). Estimation of Soil Hydraulic Properties. p. 1139-1161. In M.R. 456 Carter and E.G. Gregorich (eds.) Soil Sampling and Methods of Analysis, Canadian Society 457 of Soil Science, Taylor and Francis, LLC, Boca Raton, Fl,)

458 Cote, CM, Bristow P, Charlesworth PB, Cook FJ, Thorburn FJ (2003) Analysis of soil wetting and 459 solute transport in subsurface trickle irrigation. Irrigation Science 22, 143-156.

460 Cresswell HP (2002) The Soil Water Characteristic. p. 59-84. In N McKenzie, K Coughlan and 461 HP Cresswell (eds.) Soil Physical Measurement and Interpretation for Land Evaluation. 462 CSIRO Publishing, Collingwood Australia.

463 Espino A, Mallants D, Vanclooster M, Feyen J (1995) Cautionalry notes on the use of pedotransfer 464 functions for estimating soil hydraulic properties. Agricultural Water Management 29, 235465253. 
466 Gardenas AI, Hopmans FJ, Hanson BR, Šimůnek J (2005) Two-dimensional modeling of nitrate 467 leaching for various fertigation scenarios under micro-irrigation. Agricultural Water $468 \quad$ Management 74, 219-242.

469 Gee GW, Bauder JW (1986) Particle-size analysis. p. 383-411. In A. Klute (ed.) Methods of soil 470 analysis. Part 1. Physical and mineralogical methods. ASA and SSSA, Madison, WI.

471 Hanson BR, Šimůnek J, Hopmans JW (2006) Evaluation of urea-ammonium-nitrate fertigation 472 with drip irrigation using numerical modeling. Agricultural Water Management 86, 102-113. 473 Hopmans JW, Šimůnek J, Romano N, Durner W (2002) Inverse methods. Chapter 3.6.2. in J.H. 474 Dane and G.C. Topp (eds) Methods of soil analysis. Part 4. Physical methods. SSSA, Madison, 475 WI.

476

478

479

480

481

482

483

484

485

486

487

Isbell RF (1996) The Australian soil classification. CSIRO Publishing, Collingwood, Australia.

Kandelous MM, Šimůnek J (2010a) Comparison of numerical, analytical and empirical models to estimate wetting pattern for surface and subsurface drip irrigation. Irrigation Science 28:435444.

Kandelous MM, Šimůnek J (2010b) Numerical simulations of water movement in a subsurface drip irrigation system under field and laboratory conditions using HYDRUS-2D. Agricultural Water Management 97:1070-1076.

Kandelous MM, Šimůnek J, van Genuchten MT, Malek K (2011) Soil water content distributions between two emitters of a subsurface drip irrigation system, Soil Science Society of America Journal 75(2):488-497.

Katou H, Clothier BE, Green SR (1996) Anion transport involving competitive adsorption during transient water flow in an Andisol. Soil Science Society of America Journal 60, 1368-1375. 
488 Kuntz D, Grathwohl P (2009) Comparison of steady-state and transient flow conditions on reactive transport of contaminants in the vadose soil zone. Journal of Hydrology (Amsterdam) 369, $490 \quad 225-233$.

491 Li J, Zhang J, Rao M (2005) Modeling of water flow and nitrate transport under surface drip 492 fertigation. Transactions of the ASAE 48, 627-637.

493 Li J, Zhang J, Ren J (2003) Water and nitrogen distribution as affected by fertigation of ammonium 494 nitrate from a point source. Irrigation Science 22, 19-30.

Mallants D, Antonov, D, Karastanev D, Perko J. 2007. Innovative in-situ determination of unsaturated hydraulic properties in deep Loess sediments in North-West Bulgaria. Proceedings of the $11^{\text {th }}$ International Conference on Environmental Remediation and Radioactive Waste Management (ICEM07-7202). 1-7

McKenzie N, Coughlan K, Cresswell H (2002) Soil physical measurement and interpretation for $500 \quad$ land evaluation. CSIRO, Melbourne.

501 Molinero J, Raposo JR, Galindez JM, Arcos D, Guimera J (2008) Coupled hydrogeological and 502 reactive transport modelling of the Simpevarp area (Sweden). Applied Geochemistry 23, $503 \quad 1957-1981$.

504 Moradi A, Abbaspour KC, Afyuni M (2005) Modelling field-scale cadmium transport below the 505 root zone of a sewage sludge amended soil in an arid region in Central Iran. Journal of $506 \quad$ Contaminant Hydrology 79, 187-206.

507 Nakagawa K, Hosokawa T, Wada SI, Momii K, Jinno K, Berndtsson R (2010) Modelling reactive 508 solute transport from groundwater to soil surface under evaporation. Hydrological Processes $509 \quad 24,608-617$. 
510 Patel N, Rajput TBS (2008) Dynamics and modeling of soil water under subsurface drip irrigated

$511 \quad$ onion. Agricultural Water Management 95, 1335-1349.

512 Persicani D (1995) Analysis of leaching behaviour of sludge-applied metals in two field soils.

$513 \quad$ Water, Air, and Soil Pollution 83, 1-20.

514 Phillips IR (2006) Modelling water and chemical transport in large undisturbed soil cores using 515 HYDRUS-2D. Australian Journal of Soil Research 44, 27-34.

516 Phillips IR, Bond WJ (1989) Extraction procedure for determining solution and exchangeable ions 517 on the same soil sample. Soil Science Society of America Journal 53, 1294-1297.

518 Qafoku NP, Sumner ME, Radcliffe ME (2000) Anion transport in columns of variable charge 519 subsoils: nitrate and chloride. Journal of Environmental Quality 29, 484-493.

520 Romos TB, Simunek J, Goncalves MC, Martins JC, Prazeres A, Castanheira NL, Pereira LS (2011) 521 Field evaluation of a multicomponent solute transport model in soils irrigated with saline $522 \quad$ waters. Journal of Hydrology 129-144.

523 Romos TB, Simunek J, Goncalves MC, Martins JC, Prazeres A, Pereira LS (2012) Two524 dimensional modelling of water and nitrogen fate from sweet sorghum irrigated with fresh 525 and blended saline waters. Journal of Hydrology 87-104.

526 Rassam DW, Cook FJ, Gardner EA (2002) Field and laboratory studies of acid sulphate soils. $527 \quad$ Journal of Irrigation and Drainage Engineering 128, 100 - 106.

528 Rassam DW, Cook FJ (2002) Numerical simulations of water flow and solute transport applied to 529 acid sulphate soils. Journal of Irrigation and Drainage Engineering 128, 107 - 115.

530 Rayment GE, Higginson FR (1992) Australian laboratory handbook of soil and water chemical 531 methods. Inkata Press, Melbourne. 
532 Reynolds WD, Elrick DE, Youngs EG, Amoozegar A, Booltink HWG, Bouma J (2002) Saturated

533 and field-saturated water flow parameters. In J.H. Dane and G.C. Topp (eds) Methods of soil

534 analysis. Part 4. Physical methods. SSSA, Madison, WI.

535 SAS (2003) SAS 9.1. SAS Institute Inc., Cary, USA.

536 Schaap MG, Leij FJ, van Genuchten MT (2001) ROSETTA: a computer program for estimating

537 soil hydraulic parameters with hierarchical pedotransfer functions. Journal of Hydrology

$538 \quad$ (Amsterdam) 251, 163-176.

539 Šimůnek J, Hopmans JW, Nielsen DR, van Genuchten MT (2000) Horizontal infiltration revisited

$540 \quad$ using parameter estimation. Soil Science 165, 708-717.

541 Šimůnek J, van Genuchten MT, Šejna M (2006) The HYDRUS Software Package for Simulating

542 Two- and Three-Dimensional Movement of Water, Heat, and Multiple Solutes in Variably-

543 Saturated Media, Technical Manual, Version 1.0, PC Progress, Prague, Czech Republic, pp.

544241.

545 Šimůnek J, Šejna M, Saito H, Sakai M, van Genuchten and MT (2008) The HYDRUS-1D Software

546 Package for Simulating the Movement of Water, Heat, and Multiple Solutes in Variably

547 Saturated Media, Version 4.0, HYDRUS Software Series 3, Department of Environmental

548 Sciences, University of California Riverside, Riverside, California, USA, pp. 315.

549 Siyal AA, Skaggs TH (2009) Measured and simulated soil wetting patterns under porous clay pipe $550 \quad$ sub-surface irrigation. Agricultural Water Management 96, 893-904.

551 Skaggs TH, Trout TJ, Šimůnek J, Shouse PJ (2004) Comparison of HYDRUS-2D simulations of 552 drip irrigation with experimental observations. Journal of Irrigation and Drainage $553 \quad$ Engineering 130, 304-310. 
554 Smiles DE, Philip JR, Knight JH, Elrick DE (1978) Hydrodynamic dispersion during absorption 555 of water by soil. Soil Science Society of America Journal 42, 229-234.

556 Sonnleitner MA, Abbaspour KC, Schulin R (2003) Hydraulic and transport properties of the plant557 soil system estimated by inverse modelling. European Journal of Soil Science 54, 127-138.

558 Soil Survey Staff (1992) Keys to soil taxomony. 4th Edn. Soil Management Support Service

559 Technical Monograph No. 6. Virginia Polythechic Institute and State University, $560 \quad$ Blacksburg, VA.

561 Sposito G (1989) The chemistry of soils. Oxford University Press, New York, NY.

562 Van Dam JC, Stricker JNM, Droogers P (1994) Inverse method to determine soil hydraulic 563 functions from multistep outflow experiments. Soil Science Society of America Journal 58, 564 $647-652$.

van Genuchten MT (1980) A closed-form equation for predicting the hydraulic conductivity of unsaturated soils. Soil Science Society of America Journal 44, 892-898.

Vrugt, JA, Bouten W, Validity of first order approximations for assessing parameter uncertainty in soil hydrological models. Soil Science Society of America Journal 66, 1740-1751.

Wagenet RJ, Hutson JL (1989) LEACHM: Leaching estimation and solute movement - a processed based model of water and solute movement, transformations, plant uptake and chemical reactions in the unsaturated zone. Continuum volume 2. Water Resources Institute, Cornell University, Ithica, NY.

574 Walkley A, Black IA (1934) An examination of the Degtjareff method for determining soil organic 575 matter and a proposed modification of the chromic acid titration method. Soil Science 37, 3928. 
577 Wöhling, Th., Barkle, G.F., Vrugt, J.A. (2008). Comparison of three multiobjective optimization 578 algorithms for inverse modeling of vadose zone hydraulic properties. Soil Science Society of 579 America Journal 72(2), Soil Science Society of America Journal 305-319.

580

581 Wu G, Chieng ST (1995a) Modeling multicomponent reactive chemical transport in nonisothermal 582 unsaturated/saturated soils. Part 1. Mathematical model development. Transactions of the $583 \quad$ Asae 38, 817-826.

584 Wu G, Chieng ST (1995b) Modeling multicomponent reactive chemical transport in nonisothermal 585 unsaturated/saturated soils. Part 2. Numerical simulations. Transactions of the Asae 38, 827$586 \quad 838$ 


\section{Table $\mathbf{1}$ (on next page)}

Soil chemical and physical properties for the surface soil (0-15 cm depth). 
1 Table 1. Soil chemical and physical properties for the surface soil $(0-15 \mathrm{~cm}$ depth).

2

\begin{tabular}{|c|c|c|c|c|c|c|}
\hline $\mathrm{pH}$ & 5.8 & & & & & \\
\hline $\mathrm{EC}\left(\mathrm{mS} \mathrm{cm}^{-1}\right)$ & 0.10 & & & & & \\
\hline Soil solution cations & $\mathrm{Ca}$ & $\mathrm{K}$ & $\mathrm{Mg}$ & $\mathrm{Na}$ & $\mathrm{NH}_{4}-\mathrm{N}$ & \\
\hline$\left(\mu \mathrm{mol}_{\mathrm{c}} \mathrm{cm}^{-3}\right.$ soil solution $)$ & 46.5 & 19.96 & 11.04 & 18.32 & 13.33 & \\
\hline Soil solution anions & NO3-N & $\mathrm{Cl}$ & $\mathrm{PO}_{4}-\mathrm{P}$ & $\mathrm{SO}_{4}-\mathrm{S}$ & & \\
\hline$\left(\mu \mathrm{mol}_{\mathrm{c}} \mathrm{cm}^{-3}\right.$ soil solution $)$ & 45.84 & 15.07 & 0.52 & 2.90 & & \\
\hline Exchangeable cations & $\mathrm{Ca}$ & $\mathrm{K}$ & $\mathrm{Mg}$ & $\mathrm{Na}$ & & \\
\hline$\left(\mu \mathrm{mol}_{\mathrm{c}} \mathrm{g}^{-1}\right.$ soil $)$ & 827.46 & 114.17 & 83.34 & 0 & & \\
\hline Organic carbon $(\%)$ & 4.73 & & & & & \\
\hline Particle size distribution (\%) & sand & silt & clay & & & \\
\hline OC removed & 80 & 12 & 8 & & & \\
\hline $\begin{array}{l}\mathrm{OC} \text { and iron oxides } \\
\text { removed }\end{array}$ & 45 & 22 & 33 & & & \\
\hline \multirow[t]{2}{*}{ Clay mineralogy (\%) } & Quartz & amorphous & Kaolinite, organic & Garnet, Gibbsite & Epidote & $\begin{array}{c}\text { Smectite, Rutile, } \\
\text { Amphibole }\end{array}$ \\
\hline & $25-35$ & $15-25$ & $10-15$ & $5-10$ & $2-5$ & $<5$ \\
\hline
\end{tabular}

3

4 


\section{Table 2 (on next page)}

Parameter estimation results for the Fit All and Set Measured parameter sets. 
1 Table 2. Parameter estimation results for the Fit All and Set Measured parameter sets.

2

\begin{tabular}{lccccccc}
\hline $\begin{array}{l}\text { Inverse } \\
\text { scenario }\end{array}$ & $\begin{array}{c}\theta_{r} \\
\left(\mathrm{~cm}^{3} \mathrm{~cm}^{-3}\right)\end{array}$ & $\begin{array}{c}\theta_{s} \\
\left(\mathrm{~cm}^{3} \mathrm{~cm}^{-3}\right)\end{array}$ & $\begin{array}{c}\alpha \\
\left(\mathrm{cm}^{-1}\right)\end{array}$ & & $\begin{array}{c}K_{\text {sat }} \\
\left(\mathrm{LT}^{-1}\right)\end{array}$ & $l$ & $\Phi$ \\
\hline Fit All & 0.112 & 0.560 & 0.036 & 2.030 & 0.115 & 3.847 & 0.014 \\
& $(0.247)$ & $(0.007)$ & $(0.006)$ & $(0.684)$ & $(0.061)$ & $(5.442)$ & \\
Set Measured & 0.054 & 0.580 & 0.038 & 2.335 & 0.104 & 3.175 & 0.020 \\
& $\left(0.003^{*}\right)$ & $\left(0.04^{*}\right)$ & $(0.005)$ & $(0.279)$ & $\left(0.029^{*}\right)$ & $(0.578)$ & \\
\end{tabular}

3

4

Values in parentheses show the $95 \%$ confidence intervals of the estimated parameters. $\Phi$ indicates the

5 value of the objective function.

6

*Independently measured

7

8 


\section{Table $\mathbf{3}$ (on next page)}

Correlation matrix of the inverse function. 
1 Table 3. Correlation matrix of the inverse function.

2

\begin{tabular}{lcrrrrr}
\hline Fit All & $\theta_{r}$ & \multicolumn{1}{c}{$\theta_{s}$} & $\alpha$ & \multicolumn{1}{c}{$n$} & $K_{\text {sat }}$ & $l$ \\
\hline$\theta_{r}$ & 1.000 & & & & & \\
$\theta_{s}$ & 0.016 & 1.000 & & & & \\
$\alpha$ & $\mathbf{0 . 9 7 7}$ & -0.046 & 1.000 & & & \\
$n$ & 0.656 & -0.243 & 0.561 & 1.000 & & \\
$K_{\text {sat }}$ & -0.753 & 0.118 & -0.649 & $-\mathbf{0 . 9 7 6}$ & 1.000 & \\
$l$ & $\mathbf{- 0 . 9 7 5}$ & -0.149 & -0.941 & -0.605 & 0.737 & 1.000 \\
\hline Set Measured & $\alpha$ & $n$ & $l$ & & & \\
\hline$\alpha$ & 1.000 & & & & & \\
$n$ & $\mathbf{0 . 9 3 7}$ & 1.000 & & & & \\
$l$ & -0.283 & 0.063 & 1.000 & & & \\
\hline
\end{tabular}

3

4 


\section{Table 4 (on next page)}

Root mean square error (RMSE) of water and $\mathrm{NO}_{3}{ }^{-}$profiles determined using the Fit All and Set Measured parameters in comparison to the measured data in the horizontal column experiments presented in Fig 3. 
1 Table 4. Root mean square error (RMSE) of water and $\mathrm{NO}_{3}{ }^{-}$profiles determined using the Fit All 2 and Set Measured parameters in comparison to the measured data in the horizontal column experiments presented in Fig 3.

\begin{tabular}{lcccc}
\hline Inverse scenario & \multicolumn{2}{c}{$\begin{array}{c}\theta_{v} \\
\left(\mathrm{~cm}^{3} \mathrm{~cm}^{-3}\right)\end{array}$} & \multicolumn{2}{c}{$\begin{array}{c}\mathrm{NO}_{3}^{-} \\
\left(\mu \mathrm{mol}_{\mathrm{c}} \mathrm{cm}^{-3} \text { soln }\right)\end{array}$} \\
\hline Fit All & RMSE & $R^{2}$ & RMSE & $R^{2}$ \\
Set Measured & 0.04 & 0.89 & 7.50 & 0.97 \\
Measured $\dagger$ & 0.05 & 0.91 & 7.96 & 0.97 \\
\hline
\end{tabular}

$\uparrow$ "Measured" indicates the variation in the measured data calculated from the second set of horizontal soil columns where two $\mathrm{NO}_{3}{ }^{-}$and water measurements were made at identical points and times.

7 


\section{Table 5 (on next page)}

Root mean square error (RMSE) of the fit of the two parameter sets used to predict water and $\mathrm{NO}_{3}{ }^{-}$distribution in the wedge experiments. 
1 Table 5: Root mean square error (RMSE) of the fit of the two parameter sets used to predict water 2 and $\mathrm{NO}_{3}{ }^{-}$distribution in the wedge experiments.

\begin{tabular}{lccccc}
\hline \multirow{2}{*}{ Parameters } & $\begin{array}{l}\text { Irrigation } \\
\text { treatment }\end{array}$ & \multicolumn{2}{c}{$\theta_{v}\left(\mathrm{~cm}^{3} \mathrm{~cm}^{-3}\right)$} & \multicolumn{2}{c}{$\mathrm{NO}_{3}^{-}\left(\mu \mathrm{mol}_{\mathrm{c}} \mathrm{cm}^{-3}\right.$} \\
& & RMSE & $R^{2}$ & RMSE & $R^{2}$ \\
\hline \multirow{2}{*}{ Fit All } & Scenario A & 0.04 & 0.94 & 2.40 & 0.95 \\
\multirow{3}{*}{ Set Measured } & Scenario B & 0.03 & 0.97 & 3.05 & 0.81 \\
& Scenario A & 0.04 & 0.96 & 2.16 & 0.95 \\
& Scenario B & 0.02 & 0.98 & 3.43 & 0.76
\end{tabular}

3

$\begin{array}{lll}\text { Measured } \dagger & 0.03 & 2.64\end{array}$

$\dagger$ "Measured" RMSE values indicate the variation in the measured data calculated from the wedge experiments from Irrigation Scenario $\mathrm{B}$ columns where two $\mathrm{NO}_{3}^{-}$and water measurements were made at identical points in the wedges. 
Figure 1 (on next page)

Geometry of the wedge apparatus. 


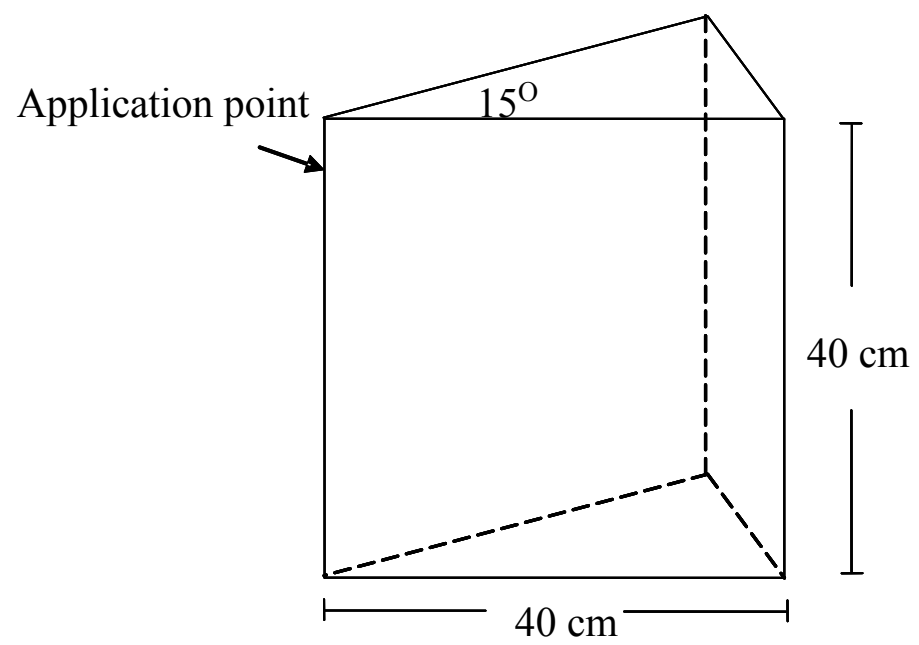


Figure 2 (on next page)

Schematic of the two irrigation scenarios ( $A$ and $B$ ) applied to the wedge columns. 


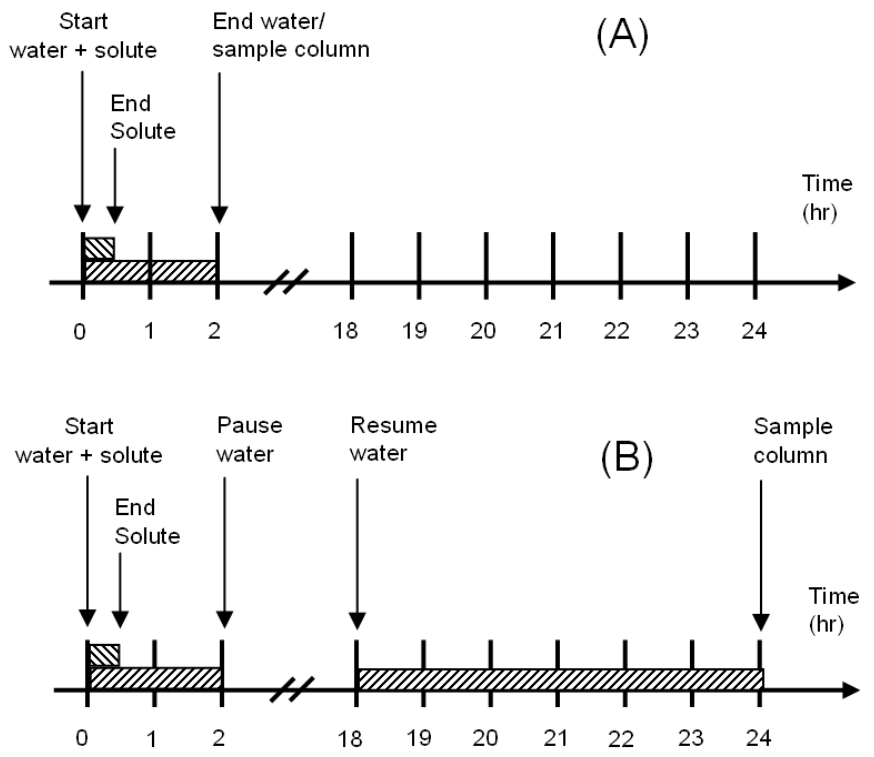




\section{Figure 3 (on next page)}

(A) Fits of the Fit All (solid line) and Set Measured (dotted line) parameters to the measured water profile data (squares) from column Set B not included in the inverse optimisation. (B) Fits for soil solution $\mathrm{NO}_{3}^{-}$ 

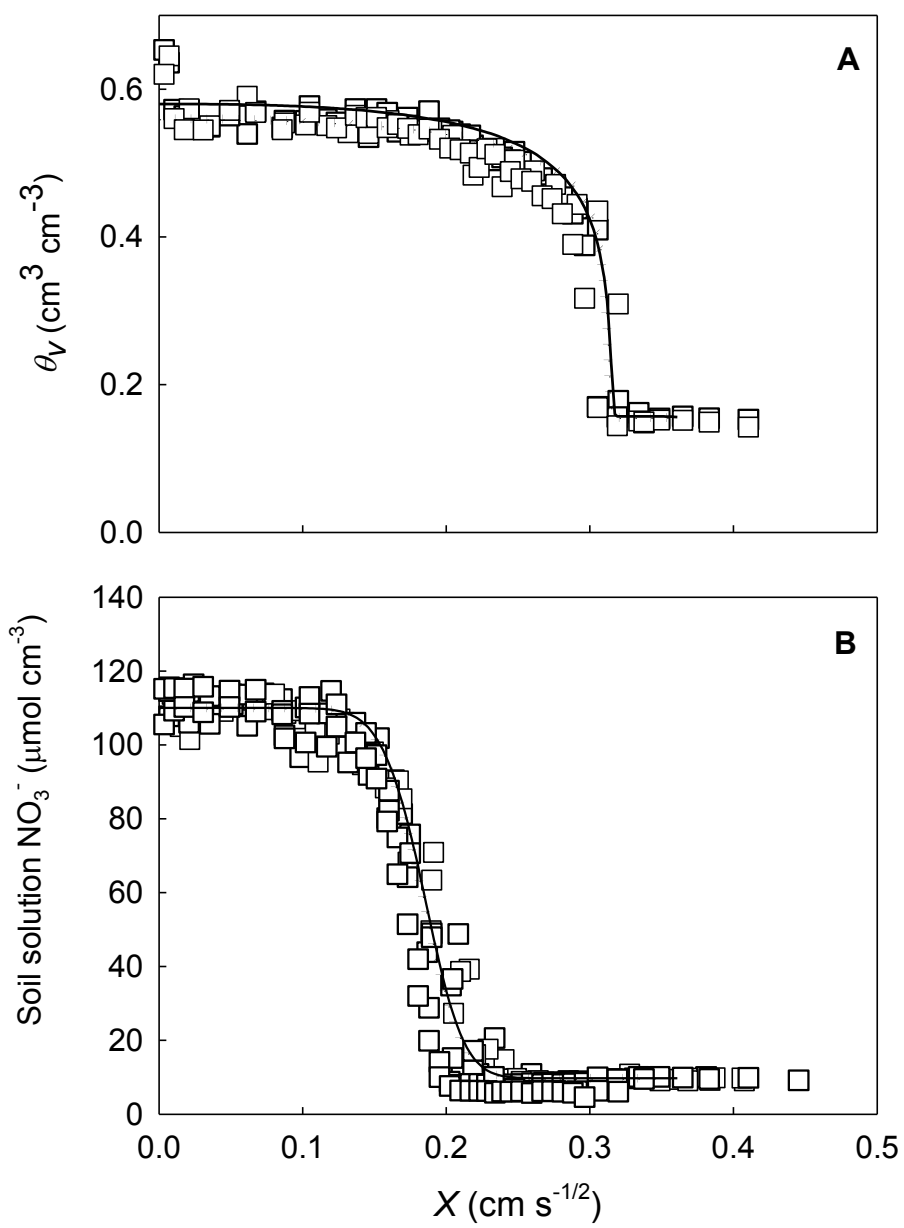


\section{Figure 4 (on next page)}

Predicted volumetric water content using Rosetta derived soil hydraulic parameters and measured water profile data (squares) against the Boltzmann variable $(X)$.

The solid line represents derived parameters using particle size data measured after removal of iron oxides and no water content data; the dash line represents parameters predicted using particle size without removing iron oxides and without water content data; the dashdot-dash line refers to parameter predicted using particle size without removing iron oxides and with soil water content at -33 and $-1500 \mathrm{kPa}$; the dash-dot-dot-dash line refers to parameters predicted using particle size after removing iron oxides and with soil water content at -33 and $-1500 \mathrm{kPa}$. 


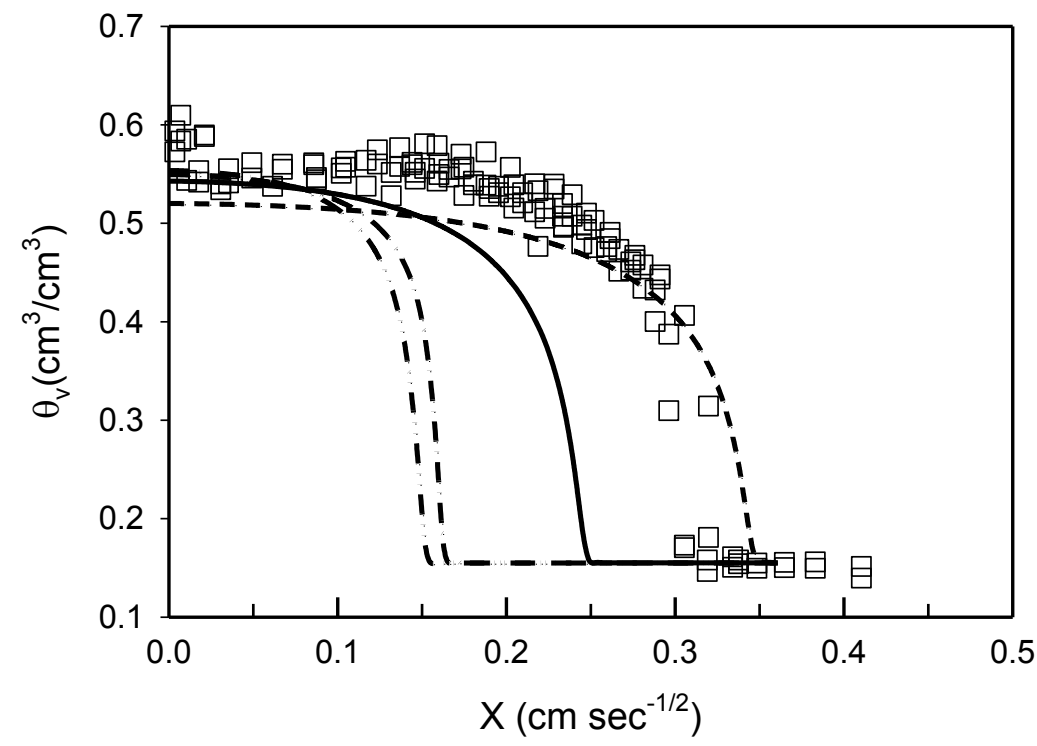


Figure $\mathbf{5}$ (on next page)

Estimation of water and $\mathrm{NO}_{3}{ }^{-}$in the wedge experiment scenario using the Set Measured parameters.

A and $\mathrm{C}$ show water content $\left(\mathrm{cm}^{3} \mathrm{~cm}^{-3}\right)$ and $\mathrm{NO}_{3}^{-}\left(\mu \mathrm{mol} \mathrm{cm}{ }^{-3}\right)$, respectively, for irrigation scenario A (2 h experiment, Fig. 2). B and D show water content $\left(\mathrm{cm}^{3} \mathrm{~cm}^{-3}\right)$ and $\mathrm{NO}_{3}^{-}(\mu \mathrm{mol}$ $\mathrm{cm}^{-3}$ ), respectively, for irrigation scenarioB (24 h experiment, Fig. 2). Horizontal and vertical transects and their symbols correspond to the water and solute profile plots in Figs 6 and 7 . 

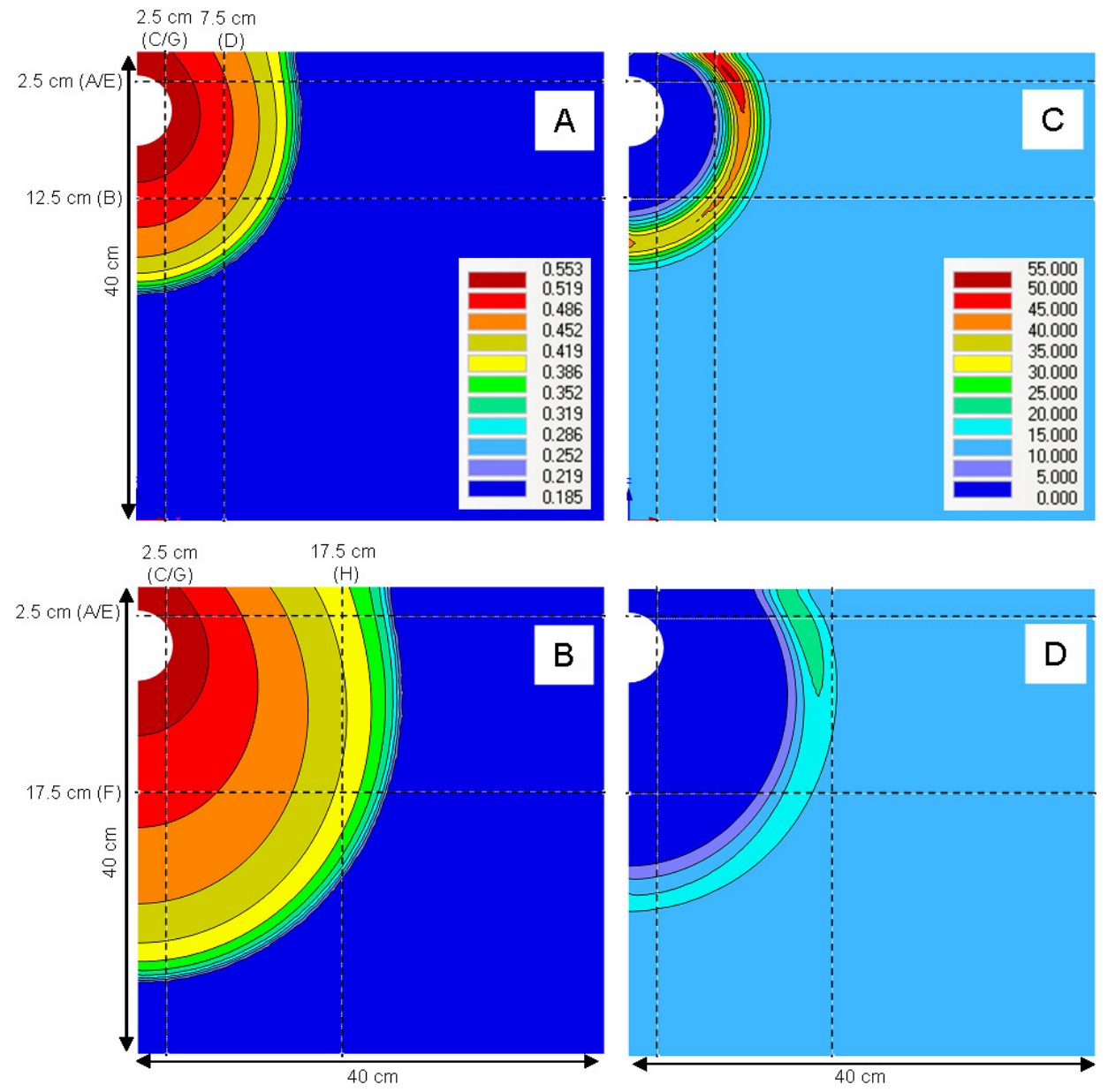


\section{Figure 6 (on next page)}

Horizontal $(A, B, E, F)$ and vertical transects $(C, D, G, H)$ of water content $\left(\mathrm{cm}^{3} \mathrm{~cm}^{-3}\right)$ in the wedge columns. The symbols indicate measured data (squares represent replicate one and triangles replicate two). Solid lines represe 

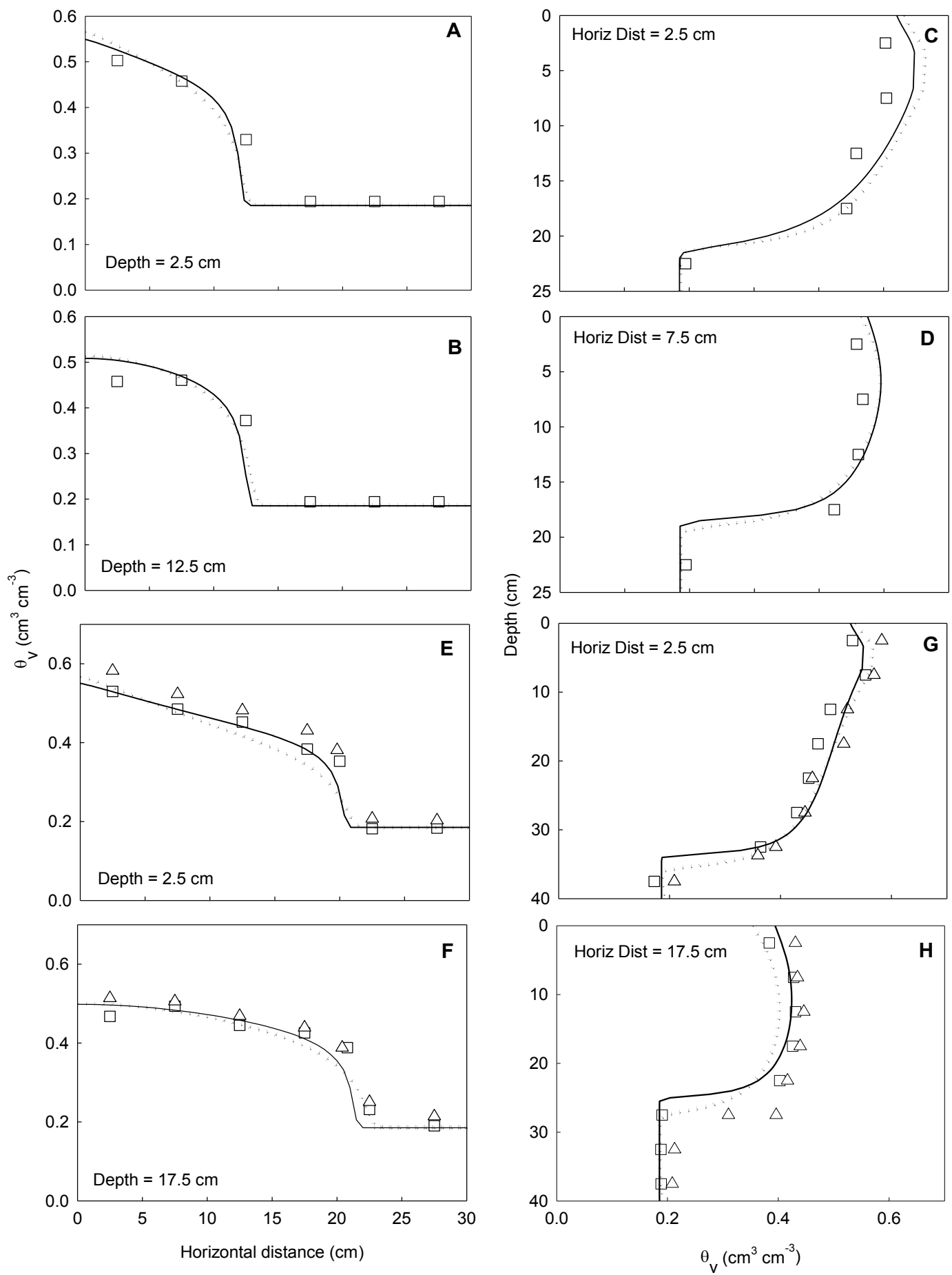
Figure 7 (on next page)

Horizontal (A, B, E, F) and vertical (C, D, G, H) transects of soil solution $\mathrm{NO}_{3}^{-}$ concentration $\left(\mu \mathrm{mol}_{\mathrm{C}} \mathrm{Cm}^{-3}\right)$ in the wedge columns.

Symbols indicate measured data (squares represent replicate one and triangles replicate two). Solid lines represent simulations using the Fit All parameters and dotted lines simulations using the Set Measured parameters. The $\mathrm{NO}_{3}{ }^{-}$reaction parameters were included in all simulations. Key to panels and transects same as for Fig. 5 . The profiles were taken at same times as snapshots shown in Fig. 5. 

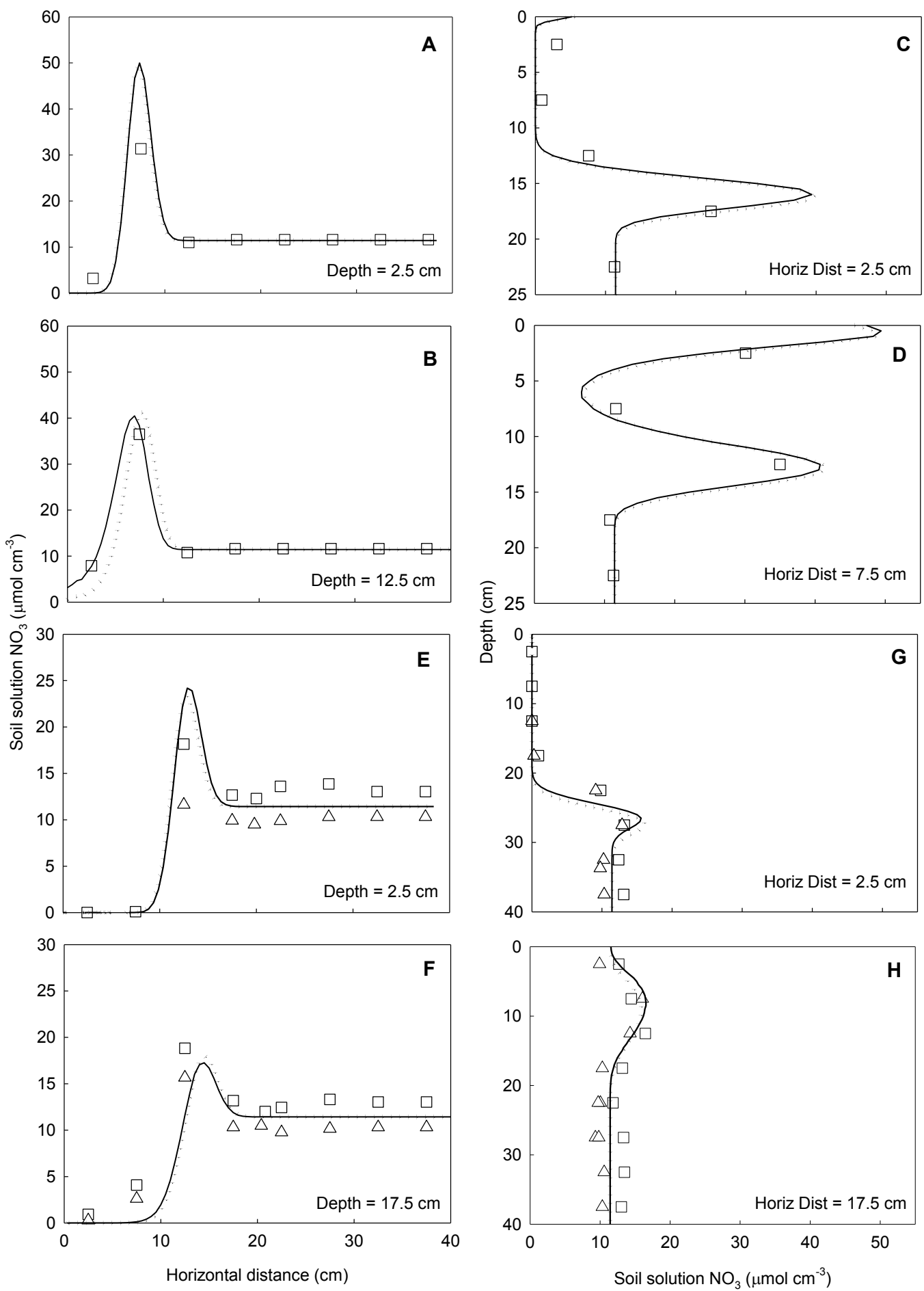